\title{
COMPLIANCE TO DIABETES SELF-MANAGEMENT IN RURAL EL-MINIA, EGYPT
}

\author{
Eman M. Mahfouz', Hala I. Awadalla ${ }^{2}$ \\ ${ }^{1}$ Department Public Health, Faculty of Medicine, El Minia University, Egypt \\ ${ }^{2}$ Institute of Environmental Studies and Research, Ain Shams University, Egypt
}

\section{SUMMARY}

Background: Diabetes is a serious public health problem that threatens the quality of life of patiens with diabetes, the success of long-term maintenance therapy for diabetes depends largely on the patients' compliance with a therapeutic plan.

Aim of this study: to assess compliance of diabetic patients to diabetes self-Management in rural El Minia, and to determine the associated factors related to it.

Subjects and Method: Cross sectional analytic study. Rural adults identified as having previously diagnosed diabetes were recruited to participate in this study. A total of 206 rural community diabetics were randomly chosen and subjected to interview questionnaire on history of diabetes, type of medication, self-management of diabetes as glucose examination, dietary modification, and eye examination.

Results: Mean age of participants was $54 \pm 6.3$ years and mean duration of diabetes was $12 \pm 8$ years. Nearly one third of the patients used insulin and more than half used oral hypoglycemic. The results of this study revealed that good adherence to diabetes self-management was reported among $41.7 \%$ of adult diabetic patients who show good adherence to diet instructions, but only $21.4 \%$ to blood glucose test. There was no gender difference regarding self care of diabetes. Younger age group had more glycemic control than older age; longer duration of diabetes was significantly associated with poor glycemic control.

Conclusion: Compliance to self-management of diabetes is suboptimal among rural adult community diabetic.

Key words: adherence, diabetic self-care, blood glucose, diet

Address for correspondence: H. I. Awadalla, Medical Science Department, Institute of Environmental Studies and Research, Ain Shams University, Abbassia Cairo, Egypt 11566. E-mail: Hala_Awadalla@yahoo.com

\section{INTRODUCTION}

Diabetes mellitus (DM) has become a problem of a great magnitude and major public health concern. In some countries, diabetes affects up to $10 \%$ of the population aged 20 years and older (1). Recent surveys show that its prevalence has been increasing in younger patients. A study done at a midwestern metropolitan area medical center showed that the incidence of type 2 diabetes increased 10 -fold in their adolescent population between 1982 and 1994 (2).

Because of the magnitude of the burden of disease, the Healthy People 2010 objectives include goals of reducing diabetes-related deaths and increasing the monitoring frequency of glucose control and chronic complications (3).

Essential health care requirements and facilities for Selfmanagement of diabetes are often inadequate in Egypt and so action is needed at all levels of health care to bridge the gap and to improve health care delivery to people with diabetes. The major components of the treatment of diabetes are: diet (combined with exercise if possible), oral hypoglycemic, and insulin treatment (1).

Diabetes is a challenging disease to manage successfully. It has been reported that non adherence rates for chronic illness regimens and for lifestyle changes are $50 \%$. As a group, patients with diabetes are especially prone to substantial regimen adherence problems. Significant patient involvement is necessary to achieve treatment goals, and diabetes care is almost always carried out by patients (4).

Adherence to the multi-component diabetic treatment regimen requires a daily care. Diabetics can live a relatively normal life but chronic complications (neuropathy, myocardial and foot ischemia, renal disease, retinopathy) can result in a substantial decline in quality of life. The Diabetes Control and Complications Trial (DCCT) confirmed that improved metabolic control was significantly associated with delayed onset and progression of microvascular complication, with a clear increasing risk related to poorer metabolic control (5).

To maintain adequate glycemic control, patients typically follow a self-management regimen involving frequent self monitoring of blood glucose (SMBG), dietary modifications, exercise, education, and medication administration. Collaboration and negotiation with health care providers, family members, and others is essential so that such behaviour changes are optimally supported and encouraged (6).

Low socioeconomic status and low levels of education have been associated with lower regimen adherence and greater diabetes-related morbidity (7). Diabetic retinopathy is one of the few ophthalmic diseases that have a defined preventive measure to delay progression of the disease and consequent visual loss (8).

Worldwide, diabetes is a major public health concern and financial burden. Research shows that, for people with diabetes, 
adhering to programs of self-management is often problematic (9). People with diabetes and their families and caregivers have a great deal to learn in order to become effective self-managers of their diabetes (10).

More than $95 \%$ of diabetes care is done by the patient, and health professionals have very little control over how patients manage their illness between office visits. Patients manage their diabetes on a daily basis within the context of the other goals, priorities, health issues, family demands, and other personal concerns that make up their lives; they have the right to set goals and decide how they will manage their illness because they have to carry out those decisions and live with the consequences (11).

The purpose of this study is to evaluate the extent of current levels of patient's adherence to diabetes self-management and their association with other sociodemographic factors.

\section{METHODS}

Design: This study applied a cross-sectional analytic household design to assess adherence to self-management of diabetes in a sample of rural adults with diabetes. The study focused on rural population because of the paucity of research concerning the diabetes self-management in this population.

The study area: El-Minia governorate is one of Upper Egypt governorates and it is $240 \mathrm{~km}$ to the south of Cairo. Tehna ElGabal and El-Burgaia villages with a population approaching 8,000 and 25,000 were located east and north to El Minia city respectively. We visited nearly 2,500 households in the two villages using a systematic random sample technique (every alternate house) asking for the presence of diabetic adults to recruit them to participate in this study. Previously diagnosed diabetics were based on self-report together with current treatment with hypoglycemic medication. Participants identified as having previously diagnosed diabetes $(n=206)$ were invited to participate in this study during the period from November 2009 to May 2010 after explaining to them the aim of the study and taking their verbal consent to be included. We used an interview questionnaire to assess diabetes self-management domains: blood glucose testing and diet.

Sample size: Sample size was calculated using the following formula: $\mathrm{n}=\mathrm{t}^{2} \times \mathrm{p}(1-\mathrm{p}) / \mathrm{m}^{2}, \mathrm{n}=$ required sample size, $\mathrm{t}=$ confidence level at $95 \%$ (standard value of 1.96), $\mathrm{p}=$ estimated prevalence of diabetes in Egypt, $\mathrm{m}=$ margin of error at 5\% (standard value of 0.05 ). The sample size was calculated based on the higher prevalence resulted in previous study, $\mathrm{n}=1.96^{2} \times 0.10(1-0.10) / 0.05^{2}$, it was calculated to be 140 individuals on estimated prevalence as reported by Herman et al. (1997) (12). The study included more subjects than the calculated sample size to compensate for any missing data in the questionnaire.

Sample: A total of 206 valid completed questionnaires were subjected to SPSS analysis.

Questionnaire: Data were collected on age, sex, education, occupation, duration of diabetes and main method of its control and clinical status was assessed.

Compliance with dietary regimen was graded as: no, less frequent and more frequent. More frequent compliance was recorded when the patient strictly followed the prescribed dietary regimen, less frequent when the patient sometimes did not follow the regimen and non compliance when he/she did not follow the regimen at all.

Compliance with anti-diabetic drugs was assessed by the extent of adherence of the diabetic patients to the prescribed doses of medications. Good compliance was recorded when diabetic patient took all medications, done all self-management in accordance with prescription.

Compliance with SMBG (self measurement of blood glucose): Responses were rated on a 6-point scale (twice a day, daily, every other day, twice a week, once a week, or never).

The research questions and hypothesis: How are the sociodemographic factors related to compliance to self-management behaviours in patients with diabetes? And to what extent the different socio-demographic factors related to diabetes control in diabetics? Our hypothesis was whether adherence to self diabetes management by rural diabetic is satisfactory or not.

The inclusion criteria required that participants are rural adults residing in the randomly chosen villages during the study period with previously diagnosed diabetes mellitus.

Exclusion criteria: Patients were excluded from the study if they were not rural dwellers, under 30 years of age and not current patients.

Justification of the study: Regimen adherence problems are common in individuals with diabetes, making glycemic control difficult to attain. The risk of complications of diabetes can be reduced by a proper adherence. Thus, patients non adherent to treatment recommendations in rural areas need to be addressed with the aim to review the scope of the adherence problem and the factors underlying it.

Implications: Rural diabetic patients could benefit from the study directly through health promotion and education brought about by the interview concerning the necessity of self-management of diabetes and the frequency of it. The diabetic patients in the community at large could be targeted by the recommendations based on the light of the results of this study.

\section{RESULTS}

Demographic variables for the 206 patients included in the sample are presented in Table 1 . The mean age was $54 \pm 6.3$ years, females represented $60.2 \%$ of the sample, mean duration of diabetes was $12 \pm 8$ years. Approximately $35 \%$ of the patients used insulin, and $57 \%$ used oral hypoglycemic. Table 2 shows that there was a statistically significant difference between age and self monitoring of blood glucose. There was no gender difference regarding self monitoring of blood glucose, nearly one quarter of males $(26.8 \%)$ as well as females $(25 \%)$ did not monitor their blood glucose. There was a significant difference in the level of educational attainment and self monitoring of blood glucose. While more than a half of illiterates $(55.5 \%)$ monitored their blood glucose less frequently, more than a half of university graduated (56.3\%) did not monitor their blood glucose at all.

Table 3 demonstrates that there were no statistically significant differences between compliance with prescribed medicine and demographic characteristics.

Table 4 summarizes the relation between compliance with dietary management of diabetes and various determinants; the majority of adults $<60$ years $(45.6 \%)$ more frequently complied 
Table 1. Characteristics of the adult rural diabetics

\begin{tabular}{|c|c|c|}
\hline Characteristics & No. & $\%$ \\
\hline \multicolumn{3}{|l|}{ Age: } \\
\hline Adults $<60$ years & 136 & 66 \\
\hline Geriatric $60-70$ years & 42 & 20.4 \\
\hline Geriatric $>70$ years & 28 & 13.6 \\
\hline Total & 206 & 100 \\
\hline \multicolumn{3}{|l|}{ Gender: } \\
\hline Male & 82 & 39.8 \\
\hline Female & 124 & 60.2 \\
\hline Total & 206 & 100 \\
\hline \multicolumn{3}{|l|}{ Occupation: } \\
\hline Nonworker & 121 & 58.8 \\
\hline Farmer & 40 & 19.4 \\
\hline Manual & 33 & 16 \\
\hline Administrator & 12 & 5.8 \\
\hline Total & 206 & 100 \\
\hline \multicolumn{3}{|l|}{ Level of education: } \\
\hline Illiterate & 128 & 62.1 \\
\hline Primary & 37 & 18 \\
\hline Secondary & 25 & 12.1 \\
\hline University & 16 & 7.8 \\
\hline Total & 206 & 100 \\
\hline \multicolumn{3}{|c|}{ Methods of diabetes control: } \\
\hline Oral & 117 & 56.8 \\
\hline Insulin & 71 & 34.5 \\
\hline Diet & 18 & 8.7 \\
\hline Total & 206 & 100 \\
\hline \multicolumn{3}{|l|}{ Duration of diabetes: } \\
\hline$<$ One year & 44 & 21.4 \\
\hline $1-5$ years & 69 & 33.5 \\
\hline$>5$ years & 93 & 45.1 \\
\hline Total & 206 & 100 \\
\hline
\end{tabular}

Mean duration of diabetes $=12 \pm 8$ years

Mean age $=54 \pm 6.3$ years

with dietary management of diabetes, while half of old people $>70$ years less frequently complied with dietary management of diabetes. There was no gender difference regarding compliance with dietary management of diabetes, the majority of females $(43.5 \%)$ were more frequently compliant with dietary management of diabetes, while most of males (47.6\%) were less frequently compliant with dietary management of diabetes.

There was a statistically significant difference between education and compliance with dietary management of diabetes, nearly one quarter $(25.8 \%)$ of illiterates were not compliant with dietary management of diabetes. Half of recently detected diabetics (less than one year) were more frequently compliant with dietary management of diabetes, however, with increasing time elapsed they became less compliant.

\section{DISCUSSION}

The present study showed that more than a half $(56.8 \%)$ of the sample were taking oral hypoglycaemic medication compared to $74.5 \%$ in United Arab Emirates (UAE), the illiteracy rate was $62.1 \%$ compared to $30.2 \%$ in UAE and the unemployment rate was $58.8 \%$ compared to $47.3 \%$ in UAE (13). Another study carried out in United States revealed that most diabetics (69\%) used oral medications, $25 \%$ used insulin, and $6 \%$ did not use any medications (14).

Diabetes is managed via a regimen of control. Physicians advise adults living with type 2 diabetes to control blood sugar levels by controlling diet, maintaining regular exercise, and complying with medication. The extent to which individuals are able to adhere to such recommendations varies (15).

Diabetes self-management behaviours such as diet and exercise involve and depend on guidance from a health care provider, meal preparation in a family context and exercising with a partner or in a group. Glucose monitoring is a relatively quick and straightforward procedure (6).

Despite the increasing prevalence of diabetes, improved understanding of the disease, and a variety of new medications, glycemic control does not appear to be improving. Self-monitoring of blood glucose (SMBG) is one strategy for improving glycemic control; however, patients adherence is suboptimal and a proper education and follow-up are crucial. SMBG should include postprandial monitoring to identify glycemic excursions after meals, to indicate the need for lifestyle adjustments, and to provide patients' feedback on dietary choices (16). Recommendations on the frequency of self-monitoring of blood glucose (SMBG) vary widely among physicians treating patients with type 2 diabetes. One SMBG per week is as sufficient and safe as four SMBG per week (17).

Nearly three quarters of the studied sample performed selfmonitoring of their blood glucose, another study reported that only $40 \%$ of patients did so (18). Self-management skills could improve with longer duration of the disease. The results of this study demonstrated that the longer duration of the disease the higher compliance with SMBG. The latter was in accordance with Mastura et al. (2007) (19).

The findings of this study revealed that non compliance with SMBG was noted in young age and high level educated subjects. On the contrary, non compliance with dietary management was seen in old and low level educated subjects. Tan and Magarey (2008) (20) reported that poor diet control was found among older subjects with low level of education. Only $8.7 \%$ were unable to comply with prescribed medicine, while in another Egyptian study adherence to prescribed medicine was $78.3 \%$ (21).

Because carbohydrate is the major secretagogue of insulin, evidence from various randomized controlled trials in recent years reported that some form of carbohydrate restriction is essential for dietary control of diabetes and that such diets are safe and effective, at least in short-term (22).

Concerning adherence to the prescribed diet, $41.7 \%, 38.8 \%$ and $19.4 \%$ were more frequent, less frequent and non compliant with dietary management of diabetes respectively, comparing these findings with Kapur et al. (2008) study (23), where they reported that $28 \%$ followed diet for the full duration of diabetes, $38 \%$ followed diet for a partial duration and $34 \%$ did not follow 
Table 2. Factors affecting self monitoring blood glucose during last month among adult rural diabetics

\begin{tabular}{|c|c|c|c|c|}
\hline \multirow[b]{2}{*}{ Factors } & \multicolumn{3}{|c|}{ Self monitoring blood glucose during last month } & \multirow[b]{2}{*}{ Total } \\
\hline & $\begin{array}{c}\text { No compliance } \\
\text { No. }(\%)\end{array}$ & $\begin{array}{l}\text { Less frequent } \\
\text { No. }(\%)\end{array}$ & $\begin{array}{l}\text { More frequent } \\
\text { No. }(\%)\end{array}$ & \\
\hline \multicolumn{5}{|l|}{ Age: } \\
\hline Adults $<60$ years & $42(30.9 \%)$ & $60(44.1 \%)$ & $34(25.0 \%)$ & $136(100 \%)$ \\
\hline Geriatric $60-70$ years & $9(21.4 \%)$ & $29(69.0 \%)$ & $4(9.5 \%)$ & $42(100 \%)$ \\
\hline Geriatric $>70$ years & $2(7.1 \%)$ & $20(71.4 \%)$ & $6(21.4 \%)$ & $28(100 \%)$ \\
\hline Total & $53(25.7 \%)$ & $109(52.9 \%)$ & $44(21.4 \%)$ & $206(100 \%)$ \\
\hline \multicolumn{5}{|c|}{$x^{2}=14.933 \quad p=0.005$} \\
\hline \multicolumn{5}{|l|}{ Gender: } \\
\hline Male & $22(26.8 \%)$ & $41(50.0 \%)$ & $19(23.2 \%)$ & $82(100 \%)$ \\
\hline Female & $31(25.0 \%)$ & $68(54.8 \%)$ & $25(20.2 \%)$ & $124(100 \%)$ \\
\hline Total & $53(25.7 \%)$ & $109(52.9 \%)$ & $44(21.4 \%)$ & $206(100 \%)$ \\
\hline \multicolumn{5}{|c|}{$x^{2}=0.492$} \\
\hline \multicolumn{5}{|l|}{ Occupation: } \\
\hline Nonworker & $29(24.0 \%)$ & $69(57.0 \%)$ & $23(19.0 \%)$ & $121(100 \%)$ \\
\hline Farmer & $13(32.5 \%)$ & $15(37.5 \%)$ & $12(30.0 \%)$ & $40(100 \%)$ \\
\hline Manual & $9(27.3 \%)$ & $19(57.6 \%)$ & $5(15.2 \%)$ & $33(100 \%)$ \\
\hline Administrator & $2(16.7 \%)$ & $6(50.0 \%)$ & $4(33.3 \%)$ & $12(100 \%)$ \\
\hline Total & $53(25.7 \%)$ & $109(52.9 \%)$ & $44(21.4 \%)$ & $206(100 \%)$ \\
\hline \multicolumn{5}{|c|}{$x^{2}=6.722$} \\
\hline \multicolumn{5}{|l|}{ Level of education: } \\
\hline Illiterate & $30(23.4 \%)$ & $71(55.5 \%)$ & $27(21.1 \%)$ & $128(100 \%)$ \\
\hline Primary & $11(29.7 \%)$ & $16(43.2 \%)$ & $10(27.0 \%)$ & $37(100 \%)$ \\
\hline Secondary & $3(12.0 \%)$ & $17(68.0 \%)$ & $5(20.0 \%)$ & $25(100 \%)$ \\
\hline University & $9(56.3 \%)$ & $5(31.3 \%)$ & $2(12.5 \%)$ & $16(100 \%)$ \\
\hline Total & $53(25.7 \%)$ & $109(52.9 \%)$ & $44(21.4 \%)$ & $206(100 \%)$ \\
\hline \multicolumn{5}{|c|}{$X^{2}=12.593 \quad p=0.050$} \\
\hline \multicolumn{5}{|l|}{ Duration of diabetes: } \\
\hline$<$ One year & $13(29.5 \%)$ & $21(47.7 \%)$ & $10(22.7 \%)$ & $44(100 \%)$ \\
\hline $1-5$ years & $18(26.1 \%)$ & $37(53.6 \%)$ & $14(20.3 \%)$ & $69(100 \%)$ \\
\hline$>5$ years & $22(23.7 \%)$ & $51(54.8 \%)$ & $20(21.5 \%)$ & $93(100 \%)$ \\
\hline Total & $53(25.7 \%)$ & $109(52.9 \%)$ & $44(21.4 \%)$ & $206(100 \%)$ \\
\hline \multicolumn{5}{|c|}{$X^{2}=0.780 \quad p=0.941$} \\
\hline
\end{tabular}

diet advice. The most frequent barriers to dietary adherence are low education and long duration of diabetes. The most frequent barriers to dietary adherence are encountered as a result of inability to provide diet self-management training and to get the right messages across to change eating behaviour (23).

The result of the current study showed that younger age subjects and the ones recently diagnosed diabetics were more compliant with dietary management of diabetes, while Kapur et al. (2008) (23) revealed that older age group and shorter duration had a positive impact on compliance.

Relatively little is known about the relationship between and of age to glycemic control in patients with diabetes (24). In elderly diabetics, management is always on challenging task due to atypical disease presentation, oftenly absent classical symptoms, presence of other coexisting conditions that delays the diagnosis, dietary advice not followed properly and due to non-compliance with drug therapy (25).

The current study revealed that subjects falling into younger age groups had more glycemic controls than the older ones but it was not significantly associated with predicting glucose control. This finding was contradictory to Benoit et al. (2005) (3) study that found out that age was significantly associated with quality of glucose control and to El-Kebbi et al.'s (2003) (24), who found that younger patients were more obese than older patients, and would be thus expected to be more insulin resistant, and possibly require more aggressive therapy to achieve glycemic control.

Longer duration of diabetes was significantly associated with poor glycemic control, this was in contrary to Goudswaard et al. 
Table 3. Factors affecting compliance with prescribed medicine of diabetes during last month among rural adult diabetics

\begin{tabular}{|c|c|c|c|c|}
\hline \multirow[b]{2}{*}{ Factors } & \multicolumn{3}{|c|}{ Prescribed medicine of diabetes during last month } & \multirow[b]{2}{*}{ Total } \\
\hline & $\begin{array}{l}\text { Poor } \\
\text { No. (\%) }\end{array}$ & $\begin{array}{c}\text { Fair } \\
\text { No. (\%) }\end{array}$ & $\begin{array}{l}\text { Good } \\
\text { No. (\%) }\end{array}$ & \\
\hline \multicolumn{5}{|l|}{ Age: } \\
\hline Adults $<60$ years & $13(9.6 \%)$ & $52(38.2 \%)$ & $71(52.2 \%)$ & $136(100 \%)$ \\
\hline Geriatric $60-70$ years & $2(4.8 \%)$ & $14(33.3 \%)$ & $26(61.9 \%)$ & $42(100 \%)$ \\
\hline Geriatric $>70$ years & $3(10.7 \%)$ & $10(35.7 \%)$ & $15(53.6 \%)$ & $28(100 \%)$ \\
\hline Total & $18(8.7 \%)$ & $76(36.9 \%)$ & $112(54.4 \%)$ & $206(100 \%)$ \\
\hline \multicolumn{5}{|c|}{$x^{2}=1.770$} \\
\hline \multicolumn{5}{|l|}{ Gender: } \\
\hline Male & $4(4.9 \%)$ & $35(42.7 \%)$ & $43(52.4 \%)$ & $82(100 \%)$ \\
\hline Female & $14(11.3 \%)$ & $41(33.1 \%)$ & $69(55.6 \%)$ & $124(100 \%)$ \\
\hline Total & $18(8.7 \%)$ & $76(36.9 \%)$ & $112(54.4 \%)$ & $206(100 \%)$ \\
\hline \multicolumn{5}{|c|}{$x^{2}=3.654$} \\
\hline \multicolumn{5}{|l|}{ Occupation: } \\
\hline Nonworker & $13(10.7 \%)$ & $41(33.9 \%)$ & $67(55.4 \%)$ & $121(100 \%)$ \\
\hline Farmer & $4(10.0 \%)$ & $18(45.0 \%)$ & $18(45.0 \%)$ & $40(100 \%)$ \\
\hline Manual & $0(.0 \%)$ & $12(36.4 \%)$ & $21(63.6 \%)$ & $33(100 \%)$ \\
\hline Administrator & $1(8.3 \%)$ & $5(41.7 \%)$ & $6(50.0 \%)$ & $12(100 \%)$ \\
\hline Total & $18(8.7 \%)$ & $76(36.9 \%)$ & $112(54.4 \%)$ & $206(100 \%)$ \\
\hline \multicolumn{5}{|c|}{$x^{2}=5.834$} \\
\hline \multicolumn{5}{|l|}{ Level of education: } \\
\hline Illiterate & $14(10.9 \%)$ & $44(34.4 \%)$ & $70(54.7 \% 0$ & $128(100 \%)$ \\
\hline Primary & $2(5.4 \%)$ & $16(43.2 \%)$ & $19(51.4 \%)$ & $37(100 \%)$ \\
\hline Secondary & $2(8.0 \%)$ & $9(36.0 \%)$ & $14(56.0 \%)$ & $25(100 \%)$ \\
\hline University & $0(.0 \%)$ & $7(43.8 \%)$ & $9(56.3 \%)$ & $16(100 \%)$ \\
\hline Total & $18(8.7 \%)$ & $76(36.9 \%)$ & $112(54.4 \%)$ & $206(100 \%)$ \\
\hline \multicolumn{5}{|c|}{$x^{2}=3.513$} \\
\hline \multicolumn{5}{|l|}{ Duration of diabetes: } \\
\hline$<$ One year & $4(9.1 \%)$ & $18(40.9 \%)$ & $22(50.0 \%)$ & $44(100 \%)$ \\
\hline $1-5$ years & $5(7.2 \%)$ & $23(33.3 \%)$ & $41(59.4 \%)$ & $69(100 \%)$ \\
\hline$>5$ years & $9(9.7 \%)$ & $35(37.6 \%)$ & $49(52.7 \%)$ & $93(100 \%)$ \\
\hline Total & $18(8.7 \%)$ & $76(36.9 \%)$ & $112(54.4 \%)$ & $206(100 \%)$ \\
\hline \multicolumn{5}{|c|}{$x^{2}=1.246$} \\
\hline
\end{tabular}

(2004) (26). This might be explained by the fact that as duration of the disease increases, parallely with increasing age of patients, diabetes causes greater decline in physical and functional status in elderly diabetics compared to the younger ones. This consequently leads to poor control of the disease (25).

\section{Limitation}

The data are cross-sectional which cannot resolve the direction of causal relations underlying associations between variables. Data on duration of diabetes and self monitoring of blood glucose were obtained by self-report and may be limited by recall and other biases. The assessment of compliance to diabetes self-management is often difficult, due to changing operational definitions, lack of patient behaviour observations, or social desirability bias in patients reporting their self-management behaviours.

\section{CONCLUSION AND RECOMMENDATION}

Findings of this study revealed that good adherence to diabetes self-management was reported in $41.7 \%$ of adult diabetic patients who showed good adherence to diet instructions, but only $21.4 \%$ to blood glucose test. It can be concluded that adherence to self-management of diabetes is suboptimal among rural adult diabetic community. Longer duration of diabetes was significantly associated with poor glycemic control. Interventions aiming at 
Table 4. Factors affecting compliance with dietary management of diabetes during last month among adult rural diabetics

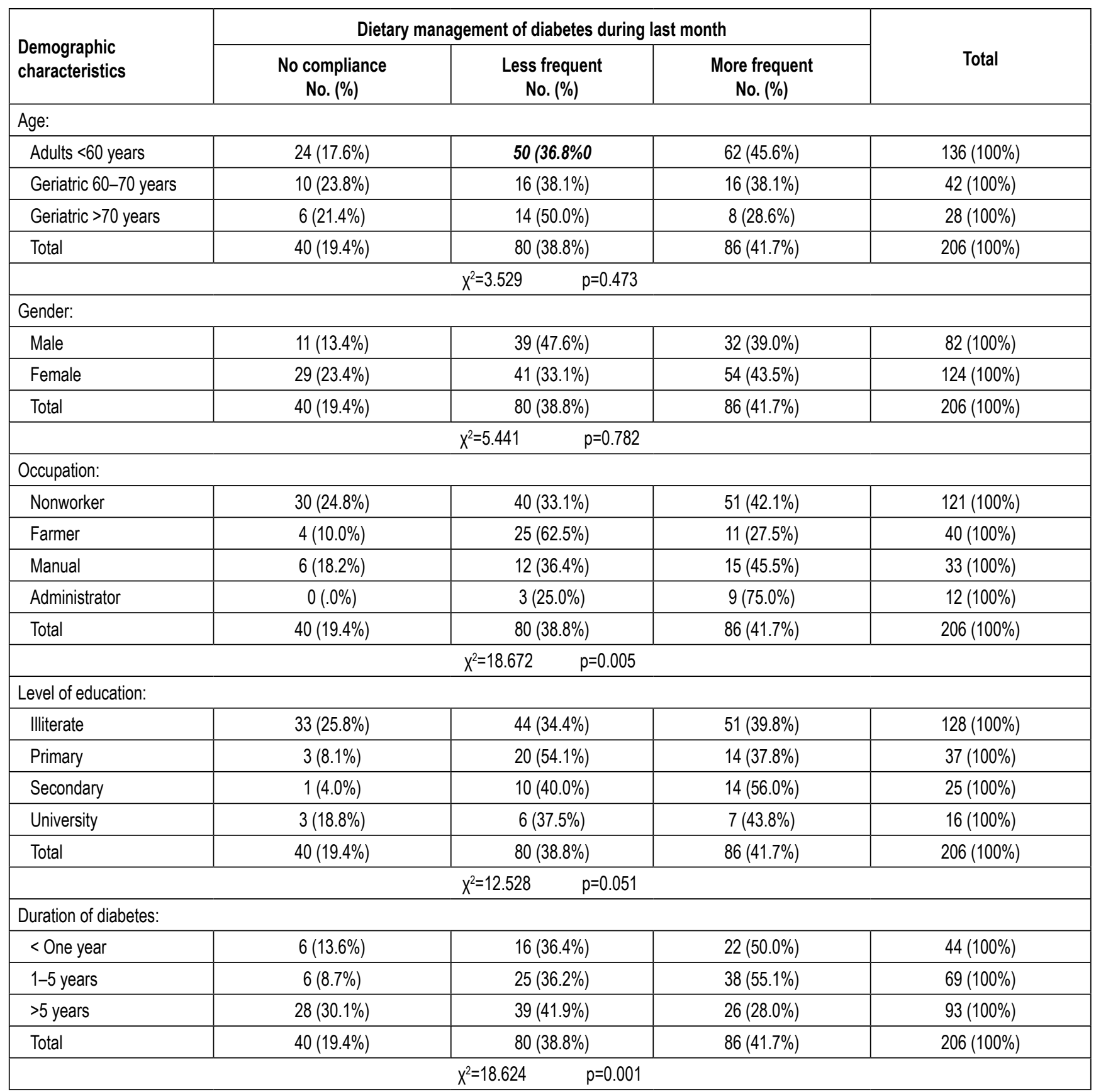

improving diabetes control should be multifaceted and should involve more effective measures of weight control and more frequent clinic visits and should increase patients' adherence to treatment regimens. Family members should be informed about their important roles in encouraging patients to undergo a glycemic control. Education through a multidisciplinary approach may improve the glycemic control in selected elderly patients with DM. Policy decisions for improving diabetes outcome should target barriers to health care access and focus on developing programs to help population groups at high-risk. As to the adherence to the prescribed diet, patients should be well informed and the diet regimens are recommended to be simplified.

\section{Ethical approval}

Informed consent was taken from every participant who agreed to be included in this study before recruitment in the study. Data confidentiality was preserved according to the revised Helsinki Declaration of Bioethics.

\section{REFERENCES}

1. Alwan AAS, editor. Management of diabetes mellitus: standards of care and clinical practice guidelines. Alexandria (Egypt): WHO Regional Office for the Eastern Mediterranean; 1994.

2. Pinhas-Hamiel O, Dolan LM, Daniels SR, Standiford D, Khoury PR, Zeitler P. Increased incidence of non-insulin-dependent diabetes mellitus among adolescents. J Pediatr. 1996 May;128(5 Pt 1):608-15. 
3. Benoit SR, Fleming R, Philis-Tsimikas A, Ji M. Predictors of glycemic control among patients with Type 2 diabetes: a longitudinal study. BMC Public Health. 2005 Apr 17;5:36.

4. Kurtz SM. Adherence to diabetes regimens: empirical status and clinical applications. Diabetes Educ. 1990 Jan-Feb;16(1):50-9.

5. Skinner TC, John M, Hampson SE. Social support and personal models of diabetes as predictors of self-care and well-being: a longitudinal study of adolescents with diabetes. J Pediatr Psychol. 2000 Jun;25(4):257-67.

6. Ciechanowski P, Russo J, Katon W, Von Korff M, Ludman E, Lin E, et al. Influence of patient attachment style on self-care and outcomes in diabetes. Psychosom Med. 2004 Sep-Oct;66(5):720-8.

7. Delamater AM. Improving patient adherence. Clin Diabetes. 2006;24(2):71-7.

8. Narendran V, John RK, Raghuram A, Ravindran RD, Nirmalan PK, Thulasiraj RD. Diabetic retinopathy among self reported diabetics in southern India: a population based assessment. Br J Ophthalmol. 2002 Sep;86(9):1014-8.

9. Nagelkerk J, Reick K, Meengs L. Perceived barriers and effective strategies to diabetes self-management. J Adv Nurs. 2006 Apr;54(2):151-8.

10. Funnell MM, Anderson RM. MSJAMA: the problem with compliance in diabetes. JAMA. 2000 Oct 4;284(13):1709.

11. Funnell MM, Brown TL, Childs BP, Haas LB, Hosey GM, Jensen B, et al. National standards for diabetes self-management education. Diabetes Care. 2007 Jun;30(6):1630-7.

12. Herman WH, Aubert RE, Ali MA, Sous ES, Badran A. Diabetes mellitus in Egypt: risk factors, prevalence and future burden. East Mediterr Health J. 1997;3(1):144-8.

13. Khattab MS, Swidan AM, Farghaly MN, Swidan HM, Ashtar MS, Darwish EA, et al. Quality improvement programme for diabetes care in family practice settings in Dubai. East Mediterr Health J. 2007 MayJun;13(3):492-504

14. Nelson KM, McFarland L, Reiber G. Factors influencing disease selfmanagement among veterans with diabetes and poor glycemic control. J Gen Intern Med. 2007 Apr;22(4):442-7.

15. Naemiratch B, Manderson L. Control and adherence: living with diabetes in Bangkok, Thailand. Soc Sci Med. 2006 Sep;63(5):1147-57.

16. Davidson J. Strategies for improving glycemic control: effective use of glucose monitoring. Am J Med. 2005 Sep;118(Suppl 9A):27S-32S
17. Scherbaum WA, Ohmann C, Abholz HH, Dragano N, Lankisch M. Effect of the frequency of self-monitoring blood glucose in patients with type 2 diabetes treated with oral antidiabetic drugs-a multi-centre, randomized controlled trial. PLoS One. 2008 Aug 28;3(8):e3087.

18. Malec K, Moleda P, Homa K, Stefański A, Raczyński A, Majkowska L. Diabetes care and self-monitoring of type 2 diabetic patients in a rural district of West-Pomeranian Province. Pol Arch Med Wewn. 2008 JanFeb;118(1-2):29-34.

19. Mastura I, Mimi O, Piterman L, Teng CL, Wijesinha S. Self-monitoring of blood glucose among diabetes patients attending government health clinics. Med J Malaysia. 2007 Jun;62(2):147-51.

20. Tan MY, Magarey J. Self-care practices of Malaysian adults with diabetes and sub-optimal glycaemic control. Patient Educ Couns. 2008 Aug;72(2):252-67.

21. Kamel NM, Badawy YA, el-Zeiny NA, Merdan IA. Sociodemographic determinants of management behaviour of diabetic patients. Part I. Behaviour of patients in relation to management of their disease. East Mediterr Health J. 1999 Sep;5(5):967-73. Erratum in: East Mediterr Health J. 1999 Nov;5(6):1242.

22. Arora SK, McFarlane SI. The case for low carbohydrate diets in diabetes management. Nutr Metab (Lond). 2005 Jul 14;2:16.

23. Kapur K, Kapur A, Ramachandran S, Mohan V, Aravind SR, Badgand $\mathrm{M}$, et al. Barriers to changing dietary behavior. J Assoc Physicians India. 2008 Jan;56:27-32.

24. El-Kebbi IM, Cook CB, Ziemer DC, Miller CD, Gallina DL, Phillips LS. Association of younger age with poor glycemic control and obesity in urban african americans with type 2 diabetes. Arch Intern Med. 2003 Jan 13;163(1):69-75.

25. Parikh AO. Drug treatment in elderly diabetic. J Indian Med Assoc. 2007 Dec;105(12):709-10

26. Goudswaard AN, Stolk RP, Zuithoff P, Rutten GE. Patient characteristics do not predict poor glycaemic control in type 2 diabetes patients treated in primary care. Eur J Epidemiol. 2004;19(6):541-5.

Received June 19, 2010 Accepted in revised form November 29, 2010 